\title{
Why Don't Philosophers Do Their Intuition Practice?
}

\author{
James Andow ${ }^{1}$
}

Received: 20 August 2018 / Accepted: 10 December 2018 / Published online: 29 December 2018

(C) The Author(s) 2018

\begin{abstract}
I bet you don't practice your philosophical intuitions. What's your excuse? If you think philosophical training improves the reliability of philosophical intuitions, then practicing intuitions should improve them even further. I argue that philosophers' reluctance to practice their intuitions highlights a tension in the way that they think about the role of intuitions in philosophy.
\end{abstract}

Keywords Intuitions $\cdot$ Expertise $\cdot$ Methodology

Do philosophers have more reliable intuitions than novices about philosophical matters? Do philosophers have expert intuitions? The idea that they do, or that they may be assumed to, has recently been entertained by a number of philosophers for a number of reasons. One area in which there has been much discussion of this idea is in debate about a so-called expertise defense of the use of intuitions in philosophy (see, e.g., Ryberg 2013; Andow 2015). I think the expertise defense fails whether or not this idea that philosophers are more reliable holds water. This paper is not about the expertise defense. Nonetheless, it is instructive to give a quick overview of one aspect of the debate about the expertise defense. It will give us some sense of the nature of the claim that philosophers have more reliable intuitions.

To understand the expertise defense, we first need to outline what it is a defense $o f$. It is a defense of a practice, which I'll call the Method of Cases, in which philosophers use intuitive judgments about cases as evidence in philosophical debates. The best

James Andow

jamesandow@gmail.com

1 University of East Anglia, Norwich, UK 
way to elaborate on that brief characterization is via examples. Let me limit myself to three. ${ }^{1}$

Permuted races What races are, or what they would be, is a central question in the philosophy of race. It is an important question, in part, because without an answer one cannot determine whether races exist. One route some philosophers have taken, to find out what races are, is to be guided by our ordinary conception of race-probing this using thought experiments to determine the extent to which our ordinary conception tracks various factors. For example, Hardimon (2017) presents the following case intended to demonstrate that our conception of races includes the notion that races are ancestry groups. The intuition that seems to be playing an evidential role is in bold. The crucial question, for Hardimon, is "whether it is conceptually possible to have races (plural) that aren't ancestry groups" and he continues,

This question can be addressed by supposing that-somehow!-a generation of "black-looking" parents gives birth to a successor generation of "whitelooking" children, and that that generation... gives birth to a successor generation of "Asian-looking" children, and that that generation...gives birth to a successor generation of "black-looking" children. We should also suppose that this process repeats itself over and over again across many generations. Now, in the permuted world, there would at any given time be groups of "whitelooking," "black-looking," and "Asian-looking" individuals. But from this, it does not follow that these groups would constitute races. Moreover, I suspect that people in the permuted world would over time cease to regard the groupsthe collections of white-looking, black-looking, and Asian-looking individuals that resulted from this process-as races. It seems to me that this would be a genuinely postracial world.

\section{Last person Sylvan argued against Basic Chauvinism (Routley 1973):}

one should be able to do what one wishes, providing (1) that one does not harm other humans and (2) that one is not likely to harm oneself irreparably

His argument swings on some putative counterexamples. The most famous: ${ }^{2}$

The last person surviving the collapse of the world system lays about them, eliminating, as far as they can, every living thing, animal, or plant (but painlessly if you like, as at the best abattoirs). What they do is quite permissible according to basic chauvinism, but on environmental grounds what they do is wrong.

\footnotetext{
${ }^{1}$ Exactly how to characterize the relevant methodology and the notion of intuitions are issues of considerable debate in the literature in philosophical methodology. For the sake of brevity, I won't defend the characterization given here. The point of this paper doesn't hang on exactly how one construes the relevant method or thinks about intuitions. The puzzle highlighted applies so long as the picture of philosophical methods is one in which the intuitions philosophers have influences the theories they end up endorsing. Similarly, one could raise questions about my characterization of the methods involved in the three examples given. However, this paper isn't the place to provide that defense.

${ }^{2}$ Language of the original updated for clarity.
} 
This strategy can't succeed unless the audience accept the claim in bold, and the author expects us to accept this claim, presumably because it is so intuitive.

Family versus Orphanage Munoz-Dardé (1999) looks for compelling reasons for not abolishing the institution of the family, given that redistribution and regulation arguably can not sufficiently compensate for the enduring effects of the initial inequalities in circumstances that families impose, i.e., "severe contraints on meeting fair equality of opportunity, or life chances, between people raised in different families." She considers a Rawlsian thought experiment in which we contrast two possible models from the original position: in model 1, children would be raised in families, social units in which "a group of elders are primarily responsible and have primary authority over a particular group of children"; in model 2, the state has overall control of childcare, an orphanage that is well-run to the extent that it is able to

equally guarantee to all children whichever conditions and principles are considered optimum for their upbringing, as long as these conditions are compatible with such an overall control.

Ultimately, she asks the reader,

I have assumed until now that the orphanage should be well-run. The question is: how probable is that, were the familiy to entirely disappear? Would not my fantasy of a generalized boarding school with teachers devoted to the individuality of each child vanish, were the state to have sole control of the upbringing of children?

urging us towards the tentative conclusion that "if generalized over many generations, an orphanage could not be well-run" and that

complete abolition of [family] would probably pose such extreme threats to individual liberty and capacity for self-determination, that it would defeat the very purpose that made us envisage its substitution by a well-run orphanage... [i.e.,] to deliver greater equal opportunity for all....

We are asked to use our intuition to determine the extent to which equality of opportunity would be provided under the two models, a judgment which then plays a key role in an argument that the family should not be abolished.

\section{2}

Why does such use of intuitions in philosophy need a defense? There are various challenges one might make to such a method. However, the challenge that is relevant for this paper concerns the reliability of intuitions. The reliability of intuitions is crucial for this philosophical method: the less reliable the intuitions provided as inputs, the less reliable the outputs of philosophical theorising using this method. Recently, the reliability of intuitions has been challenged using a particular kind of empirical finding. The relevant findings are those which suggest that intuitions about philosophical matters may vary with irrelevant factors, e.g., framing effects and 
demographic effects (see, e.g., Wiegmann et al. 2012; Weinberg et al. 2001). ${ }^{3}$ Some argue this is a sign that philosophical intuitions are unreliable. And if that's right, this generates a worry for the standard philosophical method of the method of cases.

Expertise defenses represent a particular way of resisting such worries. Numerous philosophers have responded to such worries, and defended the use of intuitions in philosophy by leaning on the idea of expert intuitions. The participants in the relevant experiments are typically non-philosophers. If philosophers may be assumed to have more reliable philosophical intuitions than the novices who are typically the participants in such experiments, then one might think the challenge to standard philosophical methodology may be resisted.

This is not a paper about expertise defenses and the line of thought I just presented is just one (rather unsophisticated) way of developing such a defense. ${ }^{4}$ What is important for my purposes is that there is an attractive picture, accepted by many philosophers, that philosophical training improves one's philosophical intuitions. This paper raises an important question for this idea. Once we take seriously the idea that philosophers have more reliable intuitions due to their greater experience in the field, a puzzle emerges.

\section{3}

Why might one expect philosophers to have more reliable philosophical intuitions? One answer is straightforward. One expects experts to have more reliable intuitions than novices about matters in their field of expertise. Chess experts have better intuitions than newcomers to the game. Mathematicians have a better intuitive sense for the prospects of proof strategies than novices. Firefighters have better intuitions about the likelihood of the collapse of a burning building. Weather forecasters have better intuitions about what the weather will be like. The idea is that something about having lots of experience in a field shapes and refines one's intuitive capacities.

Of course, experience doesn't always refine intuitions. In some domains, one should expect refinement. In other domains, there is every reason to expect no refinement at all. As Weinberg and Crowley (2009) put it: ${ }^{5}$

One of the most robust consensus findings of the study of expertise is that expert judgments can only become more reliable where experts are readily confronted

\footnotetext{
${ }^{3}$ It is important to note that number of reported demographic effects have failed to replicate, see, e.g., Seyedsayamdost (2015a, b).

${ }^{4}$ Although this is not a paper about the expertise defense, the puzzle I articulate does create problems for some versions of the defense. However, these problems pale in comparison with those it faces from other quarters (see, e.g., Machery 2012; Schulz et al. 2011; Vaesen et al. 2013; Weinberg et al. 2010). Any successful expertise defense has to deal with the growing number of experiments which suggest philosophers' intuitions also exhibit many signs of unreliability (e.g., Vaesen et al. 2013). Even if that evidence did not exist, any successful defense would have to make clear why philosophical training should be expected to make philosophers less likely to suffer from the specific types of effect highlighted by the experimental work (e.g., framing effects) (Weinberg et al. 2010, makes this point clearly).

${ }^{5}$ Kahneman and Klein (2009) review the empirical literature on intuitive expertise in two research traditions (heuristics and biases, and naturalistic decision making) and note similar themes.
} 
with clear, reliable feedback on which to train ... The fields in which competent experts routinely develop are those like meteorology, livestock judging, and chess. In such areas, experts are confronted with a truly vast array of cases, with clear verdicts swiftly realized across a wide range of degrees of complexity or difficulty. (Weinberg and Crowley 2009, p.340)

If we are to base an assumption that philosophical training improves intuitions on an analogy with other fields, then we had better pay attention to the details of that analogy. It better be that philosophy resembles more closely cases like meteorology or livestock judging than the case of horoscope writing.

One can be overly skeptical of the idea that philosophical training improves philosophical intuitions. For example, Ryberg (2013) recently attempted to cast doubt on the idea that an appropriate analogy can be drawn between philosophy (particularly moral philosophy) and expertise-conducive fields such as those mentioned by Weinberg and Crowley (2009). Ryberg (2013) argues that, unlike in other fields, there is no appropriate causal link between philosophers' experience and intuitions, and that philosophers receive no feedback about the quality of their intuitions. While some skepticism is appropriate, I think Ryberg's position goes too far.

As I have made clear in previous work (Andow 2015), there is no good reason to doubt that philosophical training influences philosophers' intuitions, and philosophers actually get quite a lot of feedback about the quality of their intuitions. Philosophers have much more experience than novices of considering thought experiments, and receive feedback in the form of indirect external corroboration. The feedback philosophers receive might not be sufficiently frequent, clear, or unambiguous to mean we should expect philosophers to be as superior to philosophical novices as meteorologists are to novices in their field, but there is nonetheless reason to expect some improvement as a result of their experience in philosophy.

It is tempting to conceptualize this greater experience that philosophers have in terms of practice. One might say that philosophers should be expected to have more reliable intuitions than novices because they have had a greater chance to practice having intuitions about hypothetical cases and so on. However, I think it would be misleading to think of philosophers' greater experience in this way. I don't think we should think of philosophical training as involving a lot of intuition practice. It may be true that a philosopher, all else being equal, will have had an intuition about a case on more occasions than someone who has never studied philosophy. Nonetheless, I contest, it is not right to say that philosophical training involves a lot of practicing having intuitions about cases.

\section{4}

Let me present a basic case for the claim that philosophers don't practice their intuitions before dealing with some objections. The basic thought makes use of an apparent disanalogy between philosophy and other fields. We do not practice having intuitions in the same way musicians practice their scales, mathematicians practice running through proofs, firefighters practice planning rescues from burning 
buildings, and weather forecasters practice predicting the weather. Not only do established professors not do their intuition practice, but neither do graduate students, nor undergraduate students.

Of course, philosophical training does involve a lot of practice of certain skills. We practice writing essays, formulating arguments, assessing the validity of arguments, drawing out the consequences of claims, constructing truth trees, and so on. And a lot of this practicing involves having intuitions. But while a lot of the practicing that we do on our way to being philosophers involves having intuitions, it doesn't involve active practicing of having intuitions. ${ }^{6}$

What would practicing having intuitions look like? Well, it would look like the kind of practice involved in the development of other expert skills. One might sit down with a list of hypothetical cases and simply practice having intuitions about them in the same way that a mathematics student might sit down and practice solving equations, or an experimental philosopher might practice running particular analyses when learning to use a new statistics package. We might send our students home with lists of philosophical cases-not to think through the consequences of saying certain things about the cases, not to think through how various theories would apply to the cases - simply to practice their skill of forming intuitive judgments about cases. Our textbooks might contain banks of hypothetical cases included in online supplemental materials: a resource for students to simply practice their intuitions out on.

We don't do this. At no point in a philosopher's career do we simply sit down with a set of cases, and go through the motions of having intuitions about them, with the purpose of improving our ability to make good intuitive judgments. Yes, we consider cases when constructing arguments, assessing theories, and so on, but never for the sake of practicing having intuitions about those cases. Yes, becoming a philosopher involves encountering a whole host of cases, and developing a familiarity with then, but cases students encounter in textbooks and classes are always embedded in a dialectical context with salient connections to relevant theories or ideas: presented not for practice but so students gain familiarity with kinds of case that play important roles in the literature.

Why don't we practice having intuitions? This lack of intuition practice in philosophy might seem somewhat surprising. Given that practicing skills is typically a really good way to refine them, and given that in other areas of expertise it is commonplace for a training regime to incorporate formal practicing of the key skills required-why is intuition practice absent from philosophy? Moreover, surely the need for practice is even greater in philosophy than in other fields. As I have pointed out in previous work (Andow 2015), although philosophers get feedback about the quality of their intuitions, and although the level of feedback might be sufficient to support

\footnotetext{
${ }^{6}$ One might be tempted to describe an expert as having some "intuitive" ability to write a good essay, as the result of much practice. Similarly, a philosopher might have an "intuitive" sense of where to look to find flaws in arguments. However, that is not the sense of an intuition which is relevant to the argument of this paper. According to the relevant sense of intuition - although it is not possible to give a characterization which is acceptable to all parties in philosophical methodology—an intuition is very roughly a judgment that a particular case has or doesn't have a particular philosophically interesting property.
} 
the assumption that philosophers' intuitions are improved by their greater experience, philosophy is still in a pretty poor position in comparison with other fields. The feedback we get about the quality of our intuitions is rarely fast, unambiguous and completely reliable. As a result, it seems natural to think, philosophers should be having to practice even more than those in other fields due to the comparative paucity of sources of feedback about the quality of their intuitions. ${ }^{7}$

In the next section, I'll consider and respond to some likely objections to the idea that this lack of practice is somehow puzzling. But before we get to that, it is worth just pausing to note that one might respond in a different way. I asked a question, "Why don't we practice having intuitions?" And, one's response might be, "Good question! What a peculiar oversight! I suppose we should start right away!"

\section{5}

Let me now anticipate and respond to a number of likely objections to the basic argument sketched so far. The objections are variations on a theme. The thought is that somehow we don't need formal intuition practice or that it wouldn't benefit us enough to be worthwhile.

Objection \#1: Informal "practice" is sufficient. Yes, we don't deliberately and explicitly practice our intuitions either as established philosophers or as philosophersin-training. It is not as if we engage explicitly in activities which have the dedicated purpose of honing our intuition-having. However, many professional skills are not developed in this way. For example, we get better at asking useful questions in talks largely not by actively practicing doing so but by doing it a lot. Likewise, our intuition practice happens during the course of everyday philosophizing and reflection. We read papers, teach, discuss, argue and contemplate the subject matter, and all these activities involve the practicing of intuition having. Whatever such practice we get is sufficient.

Response: This seems a strange attitude. Many philosophers think intuitions are the main, or a very important, source of evidence in philosophy. ${ }^{8}$ Given that sociological fact it would seem odd if, given an optimized program of activities for philosophy students, the potential for improving intuition would be so low a priority that formal and structured training of intuition-having hardly featured on the program at all. After all, wouldn't developing one's intuitive capacities be one of the main priorities in a discipline that thought intuitions were (one of) the main source(s) of evidence?

\footnotetext{
${ }^{7}$ The lack of practice is going to be particularly difficult to explain for those who endorse certain versions of the expertise defense. For it seems odd to, on the one hand, lean on the assumption that philosophers' greater experience in philosophy results in their having more reliable intuitions than novices, while, on the other hand, not incorporating any robust element of practicing having intuitions into standard philosophical training. Such a philosopher should surely think it desirable to design philosophical training in order to maximize students' (and perhaps professors' too) opportunities to gain such experiences, i.e., to build in robust programs of intuition practice.

${ }^{8}$ Although there is a vocal minority who dissent (Cappelen 2012, 2014; Molyneux 2014; Earlenbaugh and Molyneux 2009; Deutsch 2010, 2015)
} 
Perhaps informal practice is de facto sufficient for building a career in philosophy, but that isn't an excuse which has any normative force.

Objection \#2: The reason that informal practice is sufficient is that the level of intuitive expertise required in philosophy is relatively low. It may be that there are gains to be had from practicing one's intuitions in a more formal way. However, they are not necessary given that the practice one can get informally, is enough for the development of the low levels of expertise required.

Response: I certainly think it is reasonable to think that there is no need for philosophers to devote as much time and effort to intuition practice as Olympic swimmers devote to practicing swimming. Moreover, it is plausible that the reason is that the level of intuition expertise required to be a good philosopher is nothing like the level of expertise required to be a world class swimmer. However, that thought by itself doesn't excuse philosophers from their intuition practice. Maybe we shouldn't be training to the same extent as Olympic athletes, but it is still strange that we don't bother with explicit training at all, surely some training would be appropriate. The fact that we don't have any program of intuition training would only make sense if there was reason to endorse one of the following claims: (a) there are no significant gains to be made through introducing formal intuition practice or (b) the time and effort are better spent elsewhere.

Objection \#3: Maybe there are no significant gains to be made through introducing formal intuition practice.

Response: It might be, of course, that there are only minimal gains to be had from formal intuition practice (above and beyond what informal practice can provide). The lack of intuition training might be explained by considerations of bang for buck (or of diminishing returns). It might be that the improvements to intuition-having to be gained were so small (or diminished very quickly to being very small) that it made little sense to recommend students spend any significant amount of their valuable time practicing their intuitions. So perhaps the reason philosophers don't do their intuition practice is that the pay off is too small for the effort it would take. But this again seems like a pretty weird excuse-especially from those who would defend the idea that philosophers' intuitions should be expected to be more reliable than those of novices. It seems strange to (a) think that the gains provided by philosophical training as currently practiced are significant enough to shout about, and yet (b) doubt that building in concerted and focused intuition practice should be expected to have anything except a negligible impact. Perhaps there is good empirical reason to think that formalizing intuition practice in philosophy shouldn't be expected to achieve the gains over on-the-job practice that formal practice of skills achieves in other domains. However, I know of no such reason. ${ }^{9}$

Objection \#4: Maybe the time and effort are better spent elsewhere.

Response: Again, it might be the case that despite any gains to be made from formal intuition practice, the time and effort such practice would take are better spent

\footnotetext{
${ }^{9}$ Issues of burden of proof can be difficult to settle. Here, I think the burden is easy enough to settle. Given that we expect formal training to be able to afford significant advances on informal training in most other areas, the burden is on the objector here to provide a reason to think philosophical intuitions should be different.
} 
elsewhere. Students have a finite amount of time to acquire the skills and knowledge they need to be philosophers. We can't devote it all to intuition practice. So perhaps the reason philosophers don't do their intuition practice is that it isn't the best use of their time. However, absent a concrete account of what other activities-other than improving one's abilities vis-à-vis the main source of evidence in philosophy-are so valuable parts of a philosopher's training that formal intuition practice makes no appearance at all, I don't think the mere possibility helps to make much sense of the fact that philosophers don't do their intuition practice.

\section{6}

You may or may not be convinced by my responses to the four objections above. Suppose that you still want to push some such objection to my basic thought. I think it is worth taking time to consider what this kind of objection concedes. I think these kinds of objection-which aim to excuse philosophers from formal intuition practice-already concede far more than most philosophers are likely to be willing to concede. Each of the objections considered above concedes that, at least in principle, practicing one's intuitions is a good idea. Each of the objections tries to come up with an explanation for our failure to practice our intuitions and each of the objections appeals to considerations which are essentially practical, e.g., the gains would be minimal, we don't need to be any better than informal practice can achieve, and so on. All of these responses concede that, given lots of time and resources, one good way to become a better philosopher would be to engage in some formal intuition practice.

My sense is that most philosophers will be suspicious of this idea. Indeed, I suspect that to most readers of this paper the very idea of intuition practice will have seemed bizarre right from the start. I certainly suspect that few will be going straight to their next departmental meeting to propose a change to the curriculum. If that sociological claim is right, then I don't think that the objections considered above can have much going for them as explanations as to why philosophy as a discipline and philosophers as a group of people don't do their intuition practice. I do not think it is plausible that the reason we don't do our intuition practice is due to any purely practical considerations that we have have explicitly or implicitly taken into account (as individuals or as a profession).

\section{7}

So, why don't philosophers do their intuition practice? I think the clue to a better explanation goes something like this: to most philosophers the very idea of intuition practice would seem like it could only be a symptom of a really weird understanding of what role intuitions are playing in philosophy. I think that our collective distaste for intuition practice betrays something important about our understanding of the role that intuitions play in philosophy. 
There are various different hypotheses which could explain a collective distaste for intuition practice. I don't argue for any particular explanation in this paper. Nonetheless, I think it is important to give you a sense of the type of explanation which I have in mind. So, in a moment, I will consider one particular idea in a little bit of detail. First, however, I should briefly mention three other ideas which might have some mileage. (1) Perhaps the reason that philosophers don't do their intuition practice is that they secretly recognize that intuitions are of no evidential value to begin with and there's no way to polish them up. (2) Perhaps philosophers don't really think intuitions play any important role in philosophy. (3) Perhaps philosophers think intuitions play an important role but it is not an evidential one. Each of those ideas could potentially be used to explain why philosophers would have a distaste for intuition practice.

The explanation I want to explore a little is that philosophers think (or at some level are committed to the idea) that the intuitions which drive philosophy are supposed to be untutored intuitions-when relying on intuitions in philosophy the intuitions we rely on should ideally not be altered by our experience within philosophy. This is not an eccentric metaphilosophical position among those who think about the role of intuitions in philosophy, and it should be clear that a philosopher with this sort of metaphilosophical commitment could excuse themselves fairly easily from intuition practice. Indeed, if intuition practice were to have any effect at all, such a philosopher should view the effect of intuition practice as deleterious to their abilities to do good philosophy. However, of course, if one is going to explain why philosophers in general don't do their intuition practice, then one can't just focus on those philosophers with convenient explicit metaphilosophical commitments. One would also have to say that the rest of us (or a significant proportion of the rest of us) in some sense share in these commitments (or at least that some such commitments are implicit in our practice).

That said, although I don't aim to defend it here, it is not so difficult to provide some motivation for the idea that most/many philosophers think that the intuitions which play an important role in philosophy are supposed to be untutored in some important sense. One source of motivation can be found in the way we think about our students' intuitions. Which of us, when presenting our first year undergraduates with hypothetical cases, experience receiving a barrage of faulty intuitions? Few of us conceive of the responses we get in this way, I would contend, even when they are unpredictable and strange. This is not to deny that novices often response to philosophical cases in ways which are somehow off-target. Of course, it takes students a while to become accustomed to the practice of considering hypothetical cases. Trained philosophers will typically be quicker to understand the contours of cases or will be less likely to be distracted by extraneous details. But this is not a matter of their having a more reliable intuitive capacity, expert intuitions, trained intuitive responses, or anything similar. We don't, I think, tend to think of this advance in terms of our intuitions being better. Likewise, we wouldn't tend to criticize the novices for having bad intuitions, less reliable intuitions, or anything like that. Of course, this might be a matter of politeness or pedagogical nous. However, it might also be because we conceptualize the situation as one in which what students need 
to improve is not their intuitive capacities but their abilities to parse cases, recognize relevant and irrelevant features of cases, and so on. ${ }^{10}$

A second source of motivation might be found in intuition-using philosophers' typical reactions to certain kinds of project in experimental philosophy. There are very many types of project within experimental philosophy. One which has received a somewhat overblown press is the idea that philosophers' own intuitions might be supplemented by the intuitions of untutored subjects gathered empirically. The proportion of actual experimental philosophy studies which take this form is fairly tiny. But suppose that it was seriously on the table that we start using such experiments to gather intuitions instead of relying on our own intuitions. Many philosophers would probably have some worries about this proposal. But it is important to attend to the nature of those worries. One type of worry concerns whether the relevant experiments could reliably get at participants' intuitions. Philosophical cases can be difficult to grasp properly. How do we know the participants properly understand the relevant issues? How do we know whether the participants are reporting their untutored intuitions rather than drawing on some theoretical model? These worries are not about the reliability of untutored intuitions but about the reliability of the evidence about untutored judgments. I'm inclined to think that this kind of worry would be the dominant kind of worry in the minds of most who have concerns; if that is right, it speaks to a metaphilosophical outlook which says that the intuitions which play a role in philosophy should be untutored intuitions, but thinks that simply polling the folk is a bad way to get at intuitions.

\section{8}

I said that this paper would articulate a puzzle. What is the puzzle? The thought is that of the following two positions the first is more attractive: (a) philosophy is just like other fields, practice makes perfect, philosophers have more reliable intuitions than novices; (b) philosophy is somehow different, there is no reason to expect that philosophical training would somehow result in having intuitions of greater epistemic value. And that of the following two positions, the first is more attractive: (c) being pretty skeptical of the wisdom of intuition-training in philosophy; (d) being largely in favor of the idea of incorporating much more intuition practice into the standard philosophical education. The puzzle is that the natural pairs are (a) and (d) and (b) and (c) both of which incorporate one of the less attractive positions.

I didn't say I would solve the puzzle. And I won't. My main conclusion is really that philosophers who think intuitions play an important evidential role in philosophy need to make a choice. My sense is that there is a tension in most philosopher's thinking about the role of intuitions in philosophy which will make this choice a difficult one. This is a tension which the idea of doing one's intuition practice helps us to draw out. On the one hand, I think most philosophers would at least initially

\footnotetext{
${ }^{10}$ There are doubtless philosophers who do conceive of their students as having faulty intuitions. I don't contest that. But they are outliers.
} 
be reluctant to say that philosophy is importantly different from other domains in this regard and slow to agree to the idea that, while experts in other domains should be expected to have more reliable intuitions than novices, philosophers should not. On the other hand, I think most philosophers will balk at the notion of intuition practice-there is something wrong with that idea-if there is a way to improve intuitions it surely isn't to practice having intuitions! However, to reject intuition practice is really to accept an important disanalogy between philosophy and other fields. If there is reason to expect philosophers to have more reliable judgments than novices which is analogous to the reason one might expect experts in other domains to have more reliable intuitions, then intuition practice should work.

Why don't philosophers do their intuition practice? Why don't even the philosophers who explicitly appeal to the idea that philosophical training improves one's intuitions do their intuition practice? I didn't say I would solve the puzzle. But I do have my suspicions about the likely solution. At some level, I suspect the vast majority of philosophers don't really think philosophical training improves intuitions-it might improve something, but not intuitions. Some of course explicitly worry that philosophical training pollutes, rather than enhances, our intuitions. And it may well be that this sentiment is more widespread at some deep-seated level. Perhaps this is what underlies our widespread failure to do our intuition practice. As I noted above, many common reactions to certain projects in experimental philosophy and to the judgments of relative philosophical novices seem to betray an understanding that untrained untutored intuitions are the philosophically valuable intuitions and the ones we want to guide our theorizing (even if we think that consulting intuitions of untrained and untutored philosophical novices is a risky business because, e.g., it is difficult to discern whether novices have fully and properly grasped the relevant cases). However, for now, this is but one suggestion.

Perhaps you like the idea of intuition practice, but I suspect you do not.

What's your excuse?

\section{Compliance with Ethical Standards}

Conflict of Interest Statement The author declares that he has no conflict of interest.

Open Access This article is distributed under the terms of the Creative Commons Attribution 4.0 International License (http://creativecommons.org/licenses/by/4.0/), which permits unrestricted use, distribution, and reproduction in any medium, provided you give appropriate credit to the original author(s) and the source, provide a link to the Creative Commons license, and indicate if changes were made.

Publisher's Note Springer Nature remains neutral with regard to jurisdictional claims in published maps and institutional affiliations.

\section{References}

Andow, J. (2015). Expecting moral philosophers to be reliable. Dialectica, 69(2), 205-220.

Cappelen, H. (2012). Philosophy without intuitions. OUP.

Cappelen, H. (2014). X-phi without intuitions?. In Booth, A.R., \& Rowbottom, D.P. (Eds.) Intuitions. Oxford University Press. 
Deutsch, M. (2010). Intuitions, counter-examples, and experimental philosophy. Review of Philosophy and Psychology, 1(3), 447-460.

Deutsch, M. (2015). The Myth of the Intuitive. Cambridge: MIT Press.

Earlenbaugh, J., \& Molyneux, B. (2009). If intuitions must be evidential then philosophy is in big trouble. Studia Philosophica Estonica, 2, 35-53.

Hardimon, M.O. (2017). Rethinking Race: The Case for Deflationary Realism. Cambridge: Harvard University Press.

Kahneman, D., \& Klein, G. (2009). Conditions for intuitive expertise: a failure to disagree. American Psychologist; American Psychologist, 64(6), 515-526.

Machery, E. (2012). Expertise and intuitions about reference. Theoria, 27(1), 37-54.

Molyneux, B. (2014). New arguments that philosophers don't treat intuitions as evidence. Metaphilosophy, 45(3), 441-461.

Munoz-Dardé, V. (1999). Is the family to be abolished then? Proceedings of the Aristotelian Society, 99(1), $37-56$.

Routley, R. (1973). Is there a need for a new, an environmental ethic. Proceedings of the XVth World Congress of Philosophy, 1, 205-210.

Ryberg, J. (2013). Moral intuitions and the expertise defence. Analysis, 73(1), 3-9.

Schulz, E., Cokely, E.T., Feltz, A. (2011). Persistent bias in expert judgments about free will and moral responsibility: a test of the expertise defense. Consciousness and Cognition, 20(4), 1722-1731.

Seyedsayamdost, H. (2015a). On normativity and epistemic intuitions: failure of replication. Episteme, 12(1), 95-116.

Seyedsayamdost, H. (2015b). On gender and philosophical intuition: failure of replication and other negative results. Philosophical Psychology, 28(5), 642-673.

Vaesen, K., Peterson, M., van Bezooijen, B. (2013). The reliability of armchair intuitions. Metaphilosophy, 44(5), 559-578.

Weinberg, J., Gonnerman, C., Buckner, C., Alexander, J. (2010). Are philosophers expert intuiters? Philosophical Psychology, 23(3), 331-355.

Weinberg, J., Nichols, S., Stich, S. (2001). Normativity and epistemic intuitions. Philosophical Topics, 29(1 \& 2), 429-460.

Weinberg, J.M., \& Crowley, S.J. (2009). Loose constitutivity and armchair philosophy. Studia Philosophica Estonica, 2, 177-195.

Wiegmann, A., Okan, Y., Nagel, J. (2012). Order effects in moral judgment. Philosophical Psychology, $25(6), 813-836$. 